\title{
Application of Estimation of Distribution Algorithm for Feature Selection
}

DOI:

$10.1145 / 3319619.3326771$

\section{Document Version}

Accepted author manuscript

Link to publication record in Manchester Research Explorer

\section{Citation for published version (APA):}

Ayodele, M. (2019). Application of Estimation of Distribution Algorithm for Feature Selection. In The Genetic and Evolutionary Computation Conference https://doi.org/10.1145/3319619.3326771

\section{Published in:}

The Genetic and Evolutionary Computation Conference

\section{Citing this paper}

Please note that where the full-text provided on Manchester Research Explorer is the Author Accepted Manuscript or Proof version this may differ from the final Published version. If citing, it is advised that you check and use the publisher's definitive version.

\section{General rights}

Copyright and moral rights for the publications made accessible in the Research Explorer are retained by the authors and/or other copyright owners and it is a condition of accessing publications that users recognise and abide by the legal requirements associated with these rights.

\section{Takedown policy}

If you believe that this document breaches copyright please refer to the University of Manchester's Takedown Procedures [http://man.ac.uk/04Y6Bo] or contact uml.scholarlycommunications@manchester.ac.uk providing relevant details, so we can investigate your claim.

\section{OPEN ACCESS}




\title{
Application of Estimation of Distribution Algorithm for Feature Selection
}

\author{
Mayowa Ayodele \\ University of Manchester \\ Manchester, United Kingdom \\ mayowa.ayodele@manchester.ac.uk
}

\begin{abstract}
Feature selection is a machine learning concept that entails selecting relevant features while eliminating irrelevant and redundant features. This process helps to speed up learning. In this paper, an Estimation of Distribution Algorithm (EDA) is applied to a feature selection problem originating from a legal business. The EDA was able to generate a realistic solution to the real-world problem.
\end{abstract}

\section{CCS CONCEPTS}

.Computing methodologies $\rightarrow$ Discrete space search;

\section{KEYWORDS}

Feature Selection, Support Vector Machine, Estimation of Distribution Algorithm

\section{ACM Reference format:}

Mayowa Ayodele. 2019. Application of Estimation of Distribution Algorithm for Feature Selection. In Proceedings of the Genetic and Evolutionary Computation Conference 2019, Prague, Czech Republic, Fuly 13-17, 2019 (GECCO '19), 2 pages.

DOI: https://doi.org/10.1145/3319619.3326771

\section{BACKGROUND}

In recent years, feature selection has been of research interest in the computational intelligence community. It is an important preprocessing method in supervised learning. As many businesses are now collecting more and more data, feature selection is becoming increasingly important. It helps to speed up learning, improves the performance of machine learning algorithms and the quality of models [5].

In [6], feature selection approaches are categorised into filters, wrappers and embedded methods. Filters mostly differ from other methods because they use criteria that does not involve any machine learning. They are therefore used as a pre-processing step. Common examples are Pearson's correlation coefficient and information gain. Wrappers use machine learning models to evaluate the relevance of features, selection of features can be done using search algorithms like greedy search algorithms. Embedded models however perform selection as part of the construction of the model e.g L1 or L2 regularisation. Embedded methods attempt to

Permission to make digital or hard copies of part or all of this work for personal or classroom use is granted without fee provided that copies are not made or distributed for profit or commercial advantage and that copies bear this notice and the full citation on the first page. Copyrights for third-party components of this work must be honored. For all other uses, contact the owner/author(s).

GECCO '19, Prague, Czech Republic

(c) 2019 Copyright held by the owner/author(s). 978-1-4503-6748-6/19/07 ..\$15.00 DOI: https://doi.org/10.1145/3319619.3326771 reduce the computational effort required by wrappers to reclassify several feature subsets [4].

While Evolutionary Algorithms (EA) can be considered wrapper methods, they are reputable for significantly reducing the search space of solutions. When EAs are applied for feature selection, the selected machine learning model is used to evaluate each solution generated by the EA. A survey of EAs applied for feature selection such as Ant Colony Optimisation, Particle Swarm Optimisation and Genetic Algorithm is presented in [1].

Although there is no one algorithm that can be considered the best at solving all problems, Estimation of Distribution Algorithms (EDAs) have recorded competitive performances on binary problems [7]. Also EDAs can converge much quicker to good solutions than other EAs like the GA on problems they are suited for [2].

In this paper, an EDA is applied for feature selection where a fitness penalty approach is proposed to bias solutions towards less number of features. The problem considered in this paper originates from a legal business.

The rest of this paper is structured as follows. In Section 2, the feature selection problem and the business it originates from are described. Sections 3 and 4 respectively describes the solution approach and the results. Conclusions are presented in Section 5

\section{PROBLEM}

The problem presented in this paper is that of predicting the likely method of settlement for a claim. This problem originates from a legal business that represents insurance companies. It is important for the business to particularly identify matters that are likely going to be lost or won at trial. This will help the business make decisions regarding how to handle a matter. Other relevant methods of settlement are Negotiation, Part 36 Offer and Withdrawn. When a claim is settled by Negotiation, the business negotiates with the opponent claimant solicitors to get the best deal for its insurer clients. Part 36 Offer is used to describe an offer made as a tactical step designed to convince the opponent claimant solicitors to settle the claim early. The difference between Part 36 Offer and Negotiation is that there are more regulatory restrictions on Part 36 Offers than Negotiation. However, a matter may also get Withdrawn, this can happen when there is insufficient evidence by the opponent Claimant Solicitor. In summary, the methods of settlement considered in this paper are Discontinued, Lost at Trial, Negotiation, Part 36 Offer and Won at Trial.

\subsection{Problem Features}

The business captures several features when handling a matter. The features explored in this paper are presented in Table 1 
Table 1: Features

\begin{tabular}{|l|l|}
\hline Features & Description \\
\hline Damages Claimed & How much has been claimed ? \\
Claimant Solicitor & Who are opponent claimant solicitors? \\
Client & Which client are we acting for? \\
Court & What is the location of the court? \\
Person Injury? & Was there any personal injury? \\
Injury Type & What is the category of the injury sustained? \\
Prospect Grading & How complex is this matter on a scale of 1-10? \\
Reason for Instruction & Why were we instructed? \\
Branch & Which branch was instructed? \\
Team & Which team handled the claim? \\
\hline
\end{tabular}

\section{SOLUTION APPROACH}

The classification algorithm used in this study is the well-known Support Vector Machine (SVM). The SVM is used because it is one of the most stable classifiers [3].

Alg. 1 describes the EDA used in this paper.

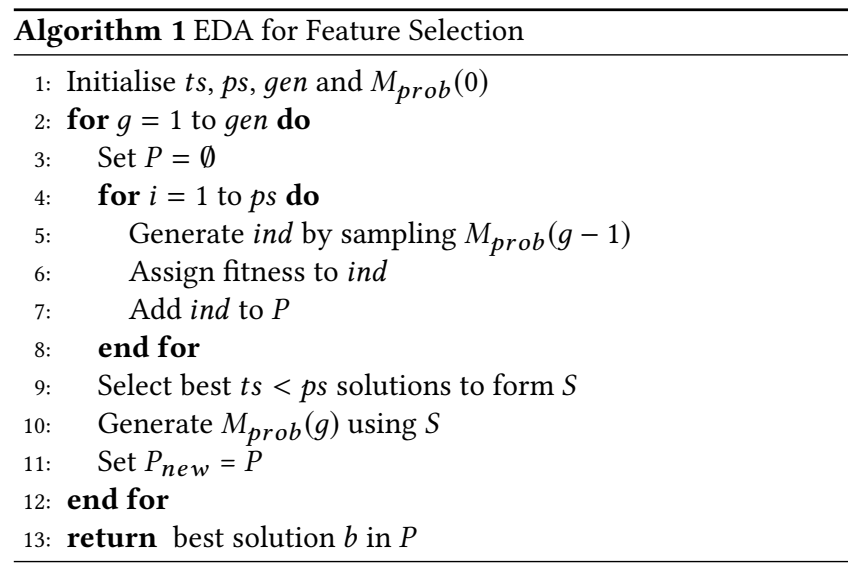

In $1, t s, p s$ and gen respectively denote truncation size, population size and number of generations. At each generation, a new probabilistic model $M_{\text {prob }}(g)$ is created and used to generate new solutions in the following generation. A new population $P_{n e w}$ is populated at each generation and completely replaces that of the previous generation $P$. The best solution $b$ is returned at the end of the run.

To generate the fitness, the Support Vector Machine (SVM) is applied to the selected features. The well-known 10-fold cross validation method is applied. The classification accuracy is then used to calculate the fitness. The fitness function is presented in 1 .

$$
f=\text { accuracy }-\left(n_{\text {features }} / 1000\right)
$$

Although the accuracy can be sufficient as the fitness function, a small penalty is applied so that the algorithm biases its search towards the lowest number of features $n_{\text {features }}$ required to get the optimal accuracy.

\subsection{EDA parameters}

The length of the solution is set to 10 which is the number of features considered in this paper while $t s$, ps and gen are respectively set to 5, 20 and 5. A total of 100 fitness evaluations has been used in this paper. A set of 3935 real-world examples was used to train the SVM.

\section{RESULTS}

In this section, results produced by the EDA are validated using the well-known feature importance method. Although the EDA was executed multiple times, the average cross-validation score produced was always 0.74 . The EDA selected Client as the only feature for predicting method of settlement.

In Table 2, the feature importance values have been generated using the Extra Tree Classifier ${ }^{1}$. The feature importance attribute of this classifier computes the relative importance of all the features.

The choice of the EDA is comparable to the feature importance method as Client has a much higher score than any of the other features.

Table 2: Features

\begin{tabular}{|l|l|l|}
\hline Rank & Feature & Importance Value \\
\hline 1 & Client & 0.481 \\
2 & Damages Claimed & 0.084 \\
3 & Claimant Solicitor & 0.080 \\
4 & Court & 0.080 \\
5 & Prospect Grading & 0.077 \\
6 & Team & 0.059 \\
7 & Injury Type & 0.056 \\
8 & Reason for Instruction & 0.051 \\
9 & Branch & 0.025 \\
10 & Personal Injury? & 0.007 \\
\hline
\end{tabular}

\section{CONCLUSION}

In this paper, an EDA has been applied for feature selection in a real-world problem which originates from a legal business. Although the problem considered is a simple one, the approach is applicable for a larger feature space. The EDA not only helps to select the feature with the highest importance but also selects the optimal number of features.

\section{REFERENCES}

[1] A Sheik Abdullah, C Ramya, V Priyadharsini, C Reshma, and S Selvakumar. 2017. A survey on evolutionary techniques for feature selection. In Emerging Devices and Smart Systems (ICEDSS), 2017 Conference on. IEEE, 58-62.

[2] Mayowa Ayodele. 2018. Effective and efficient estimation of distribution algorithms for permutation and scheduling problems. (2018)

[3] Ioan Buciu, Constantine Kotropoulos, and Ioannis Pitas. 2006. Demonstrating the stability of support vector machines for classification. Signal Processing 86, 9 (2006), 2364-2380.

[4] Girish Chandrashekar and Ferat Sahin. 2014. A survey on feature selection methods. Computers \& Electrical Engineering 40, 1 (2014), 16-28.

[5] Augusto Destrero, Sofia Mosci, Christine De Mol, Alessandro Verri, and Francesca Odone. 2009. Feature selection for high-dimensional data. Computational management science 6, 1 (2009), 25-40.

[6] Isabelle Guyon and André Elisseeff. 2006. Feature Extraction: Foundations and Applications. Springer Berlin Heidelberg.

[7] Mark Hauschild and Martin Pelikan. 2011. An introduction and survey of estimation of distribution algorithms. Swarm and evolutionary computation 1, 3 (2011), 111-128.

\footnotetext{
${ }^{1}$ https://scikit-learn.org/stable/modules/generated/sklearn.ensemble ExtraTreesClassifier.html
} 